\title{
Pernicious effect of promotion panned
}

Promotional Cultures: The Rise and Spread of Advertising, Public Relations, Marketing and Branding, by Aeron Davis. Cambridge, UK: Polity Press, 2013, 247 pp. ISBN 0745639836,

ERON DAVIS' new book pro-
motes the argument that we are increasingly submerged in promotional discourses. This book will not rescue anyone from their impending drowning but nevertheless it searches the murky waters of public relations, marketing, promotions and advertising fishing out the pervasive and unrelenting promotional influences. The author draws on numerous theories to demonstrate the cultural shift we have made to become a promotional world. It draws on established media theorists such as Adorno, Barthes, Baudrillard, Blumer, Bordieu, Fiske and McQuail as well as more recent researchers to develop the argument that promotion has become an imperceptible and intrinsic part of

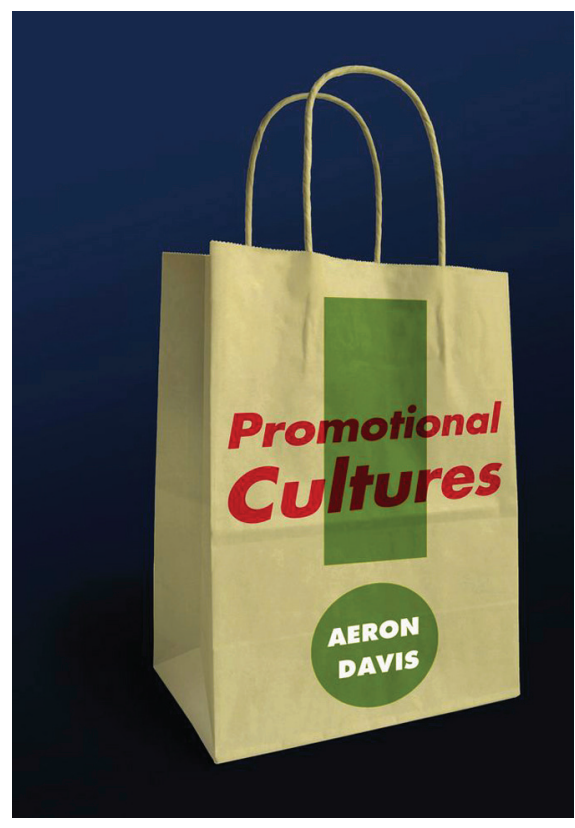

our lives. This text is likely to have greater appeal to readers with prior knowledge of mass communications, journalism or public relations as it does not explain theories but glosses over them, for example, Barthes' semiotics is briefly described as how a signifier and signified have varied individual meanings but can combine to form one sign. Davis refers to textual analysis by racing through the tools of news values, uses and gratifications, encoding and decoding, semiotics and postmodernism.

Davis questions how a promotional culture is affecting production and creating an unsustainable capitalism. He argues that promotion is 
influencing the creation of commodities and even a recreation of ourselves, it is shaping corporations, industries and markets and feeds upon itself to become an omnipotent force. The emptiness of branding is portrayed by explaining how a brand can be developed for one item only and then extended to a newly created range of more easily brandable products and services. Conundrum promotion constructs and controls an industry, such as fashion, and creates a cycle which conflicts with its associated financial cycle. Journalism does not escape the effects of a promotional culture where Davis sees public relations as providing information subsidies to resolve media cut-backs in an industry where journalism autonomy is presented as a promotion in itself.

This book argues that promotion has a pernicious and controlling effect on our lives, our opinions and even our values. Industry innovators, Gates and Jobs, are portrayed as strong marketeers and their success attributed largely to how they promoted themselves in order to get top engineers and investors to join them, on their terms. It is then suggested they created products beyond a 'use value', such as iphones and ipods which became fashion items.

Davis leaps to Hollywood to explain how promotion is a key part of a film's budget where marketing and licensing rights restrict creativity and therefore lead to formulaic films. In turn, celebrities are seen as a promotional creation. Jennifer Lopez is considered highly constructed where her race and class are 'stretched and reshaped according to audience and commercial needs' (p. 129). Davis then discusses the power of symbolic capital in a range of celebrities and how visible power can be rendered powerless. He considers David Cameron's rise in the UK Conservative party as having a celebrity-style symbolic capital owing to his promotion through personal connections, media relations and events. Tiger Woods, has an endorsement value higher than he would receive for his actual sports activities, and how his loss of 'symbolic capital', or damage to his reputation, equates to a loss of his economic capital.

Politics is attacked by Davis who claims that promotion 'feudalises' Habermas' public sphere and allows a propaganda model managed by the elite. Davis questions the effect promotion has on media and public opinion and suggests the communications objectives of political parties may also lead to distorted news content. Davis warns that politics is disengaging voters as its promotional efforts focus on swing voters, neglecting safe majorities, and claims that for many 
Obama is seen to have done little to address the needs of the disenchanted groups that he managed to persuade in the 2008 election. He also despairs of politicians' growing focus on how their policies are massaged to have media appeal.

Davis highlights the access to governments that corporations have through 'expensive' lobbying firms, and suggests that better messaging and media professionalism, i.e. promotions, could have achieved more success for the NGO advocacy campaigns Make Poverty History and the Occupy Movement.
This book offers a well-referenced analysis of a bourgeoning promotional culture which is accused of creating communication but is controlling it, encouraging creativity but stifling it, presenting a truth that is convincing but not trustworthy, allowing political communication but managing public opinion, and obscuring real powersymbolic power. Davis delivers a great insight into current culture through the lens of promotion. It will be very stimulating to academics interested in cultural studies, mass communication, the media and promotional industries.

\section{A]团 COMMUNICATIONS}

\section{POSTGRADUATEJOURNALISM}

Bachelor of Communication Studies(Hons) offers students either an applied or an academic pathway incommunication studies. Papers and strands include Asia-Pacificjournalism, digital media, investigative journalism, public relations and screen writing.

Master of CommunicationsStudies(MCS) is a postgraduateresearch degree offering practical options. Doctorate in Communication Studies (PhD) is a thesis-based research degree granted on the basis of $x$ original and substantive contribution to knowledge. TheFaculty of Designand Ereative lindustries encourages and supports innovative interdisciplinary research. The School of Communication Studies has supervisingstaff whose research interests cover a range of areas encompassing media, politics and ownership, journalism, human communication, new media and development, discourse analysis and popular culture.

Email: commstudies回aut.ac.nz | Web: www.commstudies.aut.ac.nz

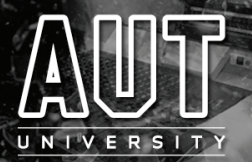

262 PACIFIC JOURNALISM REVIEW 20(1) 2014 